\title{
Safety and Efficacy of Carbon-ion Radiotherapy Alone for Stage III Non-small Cell Lung Cancer
}

\author{
MAKOTO ANZAI ${ }^{1,2}$, NAOYOSHI YAMAMOTO ${ }^{3}$, KAZUHIKO HAYASHI $^{1,2}$, \\ MIO NAKAJIMA ${ }^{3}$, AKIHIRO NOMOTO ${ }^{3}$, KAZUHIKO OGAWA ${ }^{1}$ and HIROSHI TSUJI ${ }^{3}$ \\ ${ }^{1}$ Department of Radiation Oncology, Osaka University Graduate School of Medicine, Osaka, Japan; \\ ${ }^{2}$ Osaka Heavy Ion Therapy Center, Osaka, Japan; \\ ${ }^{3}$ The QST Hospital, National Institutes for Quantum and Radiological Sciences and Technology, Chiba, Japan
}

\begin{abstract}
Background/Aim: We evaluated the efficacy and safety of carbon-ion radiotherapy (CIRT) alone for Stage III non-small-cell lung cancer (NSCLC). Patients and Methods: Data of 65 patients (median age $=73$ years) with Stage III NSCLC who underwent CIRT alone in the QST Hospital, Chiba, Japan, between 1997 and 2015 were retrospectively analysed. The median dose was 72.0 Gy (relative biological effectiveness). Results: The median follow-up was 27.6 months (range=1.6-207.7 months). Two-year local control, progression-free survival (PFS), and overall survival (OS) rates were $73.9 \%, 38.6 \%$, and $54.9 \%$, respectively. Overall, 1 (2\%), 4 (6\%), and 1 (2\%) patient developed Grade 4 (mediastinal haemorrhage), Grade 3 (radiation pneumonitis), and Grade 3 (bronchial fistula) toxicities, respectively. On univariate analysis, clinical $T$ and $N$ stage and CIRT timing were significant predictors of PFS and OS; clinical target volume was a significant predictor of PFS. Conclusion: CIRT alone is effective with acceptable toxicity for Stage III NSCLC.
\end{abstract}

Chemoradiotherapy using a platinum preparation is the standard treatment of choice for unresectable Stage IIIA and Stage IIIB non-small cell lung cancer (NSCLC). Several studies have evaluated the use of platinum-based concurrent chemoradiotherapy for patients with Stage III NSCLC, and the median overall survival (OS) was 22.0-28.7 months (1-3). Moreover, the anti-programmed death ligand 1 antibody durvalumab has been effective as consolidation therapy after platinum-based concurrent chemoradiotherapy for Stage III NSCLC (4). However, despite the survival benefits, concurrent

Correspondence to: Kazuhiko Hayashi, Department of Radiation Oncology, Osaka University Graduate School of Medicine, 2-2 Yamadaoka, Suita, Osaka 565-0871, Japan. Tel: +81 668793482, Fax: +81 668793489, e-mail: k.hayashi@osaka-himak.or.jp

Key Words: Carbon-ion radiotherapy, non-small-cell lung cancer, effectiveness, stage III, toxicity. chemoradiotherapy and consolidation therapy induced severe esophagitis, pneumonitis, and hematologic toxicity; therefore, it is sometimes not indicated for elderly patients and patients with severe comorbidities $(5,6)$. Accordingly, more effective and low-burden local therapy is desired.

Carbon-ion radiotherapy (CIRT) involves high linear energy transfer with good dose-localizing properties; it is being gradually used across Europe and Asia (7), as CIRT delivers a high dose of radiation to the target tissue, while avoiding the adjacent critical organs-at-risk. Consequently, CIRT can clinically achieve high local control (LC) rates with relatively low toxicity (8-10). Regarding the use of CIRT for locally advanced lung cancer, the 2-year LC and OS rates were $81.8 \%$ and $62.2 \%$, respectively, and no Grade $\geq 3$ toxicities were observed in a multicentre study of 64 patients with Stage II and III NSCLC (9). In another study, the 2-year LC and OS rates after CIRT alone for 141 patients with Stage II and III NSCLC were $80.3 \%$ and $58.7 \%$, respectively (10). In addition, 6 patients $(4.2 \%)$ and 1 patient (0.7\%) experienced Grade 3 and Grade 4 toxicities, respectively, and none experienced Grade 5 toxicities. Thus, these clinical outcomes indicated that CIRT alone may be a promising treatment option for Stage II and III NSCLC. However, these studies evaluated the usefulness of CIRT for Stage II and III lung cancer together (8-10), and no previous study has evaluated the outcomes with a focus on Stage III NSCLC. In addition, the efficacy of chemoradiotherapy and consolidation therapy with durvalumab has already been demonstrated for stage III NSCLC. Therefore, in the current study, we retrospectively analysed the clinical outcomes of CIRT alone in 65 patients with Stage III NSCLC.

\section{Patients and Methods}

Study design. This study was approved by the Institutional Review Board of our institution and conducted in accordance with the Declaration of Helsinki. In this retrospective analysis, we used the data of 24 patients with Stage III NSCLC from our institutional prospective phase I/II study for Stage II and III NSCLC as well as 
those of 41 patients with Stage III NSCLC who were ineligible for the phase I/II study and who received the same treatment for the same period (10). The selection criteria for this retrospective analysis were as follows: i) histologically or clinically diagnosed Stage IIIA or B NSCLC per the $7^{\text {th }}$ Edition of the UICC TNM Classification, ii) Eastern Cooperative Oncology Group performance status score of $0-2$, iii) measurable tumours, iv) patients who had unresectable tumours or those refused surgery, $v$ ) patients who received definitive treatment, vi) patients who had no other active cancers, and vii) no history of radiotherapy to the concerned region. The exclusion criteria included lung tumours with suspected invasion to the trachea, great vessels, heart, or carina. The histology or cytology was confirmed in 59 patients $(90.8 \%)$ via bronchoscopic biopsy, computed tomography (CT)-guided biopsy, or sputum cytology.

Carbon-ion radiotherapy. Patients were immobilized using an individually tailored immobilization device (Moldcare; Alcare, Tokyo, Japan; Shellfitter; Kuraray, Osaka, Japan), and CT images were obtained with the patient in the supine or prone position by using respiratory sensors to monitor the respiratory phase.

The gross tumour volume was contoured as a primary lung lesion and metastatic lymph nodes on CT images $(8,10)$. The clinical target volume (CTV) was defined as the primary lesion with a 10$\mathrm{mm}$ margin and any prophylactic lymph nodes (ipsilateral hilar and/or mediastinal lymph nodes). For N0 cases, prophylactic irradiation to the lymph nodes was omitted. In cases where the CTV was close to the organs-at-risk, the CTV was reduced. The planning target volume (PTV) was defined as the CTV plus a 5-mm safety margin to account for positioning errors. Three-dimensional treatment planning was performed using the in-house HIPLAN software (NIRS, Chiba, Japan) until May 2012 and XiO-N (ELEKTA, Stockholm, Sweden; Mitsubishi Electric, Tokyo, Japan) from April 2012 onwards. The total dose was administered to the isocentre, and it enclosed the PTV conformably, with the $95 \%$ isodose line. The prescribed dose ranged from 64.0 to $76.0 \mathrm{~Gy}$ [relative biological effectiveness (RBE)] in 16 fractions, 4 days per week. The results of our dose escalation study have been previously reported (8). Accordingly, the recommended dose was fixed at 72 Gy (RBE) in 16 fractions. Subsequently, this dose was used for all patients $(n=48,73.8 \%)$. For patients with lymph node metastasis, prophylactic irradiation to the lymph nodes was performed at a median dose of $49.5 \mathrm{~Gy}$ (RBE) $(8,10,11)$. The following irradiation dose constraints were applied: $60 \mathrm{~Gy}(\mathrm{RBE})$ to the main bronchus, $50 \mathrm{~Gy}$ (RBE) to the oesophagus, and $30 \mathrm{~Gy}$ (RBE) to the spinal cord. Irradiation was performed in 2-5 fields with 250 or $290 \mathrm{MeV}$ carbon ions (10). During each course of irradiation, the patient's position was confirmed by using a computer-aided online positioning system.

Regarding chemotherapy, 18 patients received neoadjuvant chemotherapy. Among these 18 patients, 16 underwent platinumbased induction chemotherapy and 1 patient underwent gefitinib; the history regarding chemotherapy was unclear in 1 patient. None of the 65 patients received concurrent or adjuvant chemotherapy.

Follow-up. After treatment, follow-up was performed at 1, 3, 6, 9, and 12 months, and every 3-6 months after 12 months if serious complications had not occurred. During each follow-up, chest CT, chest radiography, and a blood test were performed. If necessary, brain magnetic resonance imaging or positron emission tomography (PET) was performed.
Table I. Patient and tumour characteristics.

\begin{tabular}{|c|c|}
\hline Characteristics & Value or number $(\%)$ \\
\hline \multicolumn{2}{|l|}{ Age } \\
\hline Median, years (range) & $73(40-88)$ \\
\hline \multicolumn{2}{|l|}{ Gender } \\
\hline Male & $52(80)$ \\
\hline Female & $13(20)$ \\
\hline \multicolumn{2}{|l|}{ PS score } \\
\hline 0 & $28(43)$ \\
\hline 1 & $33(51)$ \\
\hline 2 & $4(6)$ \\
\hline \multicolumn{2}{|l|}{ Smoking status } \\
\hline Current or previous & $51(78)$ \\
\hline Never & $14(22)$ \\
\hline \multicolumn{2}{|l|}{ Interstitial pneumonia } \\
\hline Present & $3(5)$ \\
\hline Absent & $62(95)$ \\
\hline \multicolumn{2}{|l|}{ Treatment status } \\
\hline Initial treatment & $48(74)$ \\
\hline \multicolumn{2}{|l|}{ Recurrence or residual cancer after } \\
\hline \multicolumn{2}{|l|}{ Location of the primary tumour } \\
\hline Upper lobe & $53(82)$ \\
\hline Middle lobe & $2(3)$ \\
\hline Lower lobe & $10(15)$ \\
\hline \multicolumn{2}{|l|}{ Resection status } \\
\hline Resectable & $11(17)$ \\
\hline Unresectable & $54(83)$ \\
\hline \multicolumn{2}{|l|}{ Clinical T stage } \\
\hline 1 & $10(15)$ \\
\hline 2 & $22(34)$ \\
\hline 3 & $13(20)$ \\
\hline 4 & $20(31)$ \\
\hline \multicolumn{2}{|l|}{ Clinical N stage } \\
\hline 0 & $13(20)$ \\
\hline 1 & $7(11)$ \\
\hline 2 & $40(62)$ \\
\hline 3 & $5(8)$ \\
\hline \multicolumn{2}{|l|}{ Clinical stage } \\
\hline IIIA & $45(69)$ \\
\hline IIIB & $20(31)$ \\
\hline \multicolumn{2}{|l|}{ Histology of the primary lung cancer } \\
\hline Adenocarcinoma & $28(43)$ \\
\hline Squamous cell carcinoma & $23(35)$ \\
\hline Large cell carcinoma & $5(8)$ \\
\hline Non-small-cell carcinoma & $3(5)$ \\
\hline Unknown & $6(9)$ \\
\hline \multicolumn{2}{|l|}{ Irradiation field } \\
\hline Primary lesion & $11(17)$ \\
\hline Primary lesion and the hilar lymph nodes & $3(5)$ \\
\hline Primary lesion and the mediastinal lymph node & $51(78)$ \\
\hline \multicolumn{2}{|l|}{ Total dose } \\
\hline Median (range, Gy RBE) & $72(64-76)$ \\
\hline \multicolumn{2}{|l|}{ CTV } \\
\hline Median (range, $\mathrm{ml}$ ) & $423(60-1476)$ \\
\hline \multicolumn{2}{|l|}{ VC } \\
\hline Median (range, ml) & $2840(1100-5570)$ \\
\hline \multicolumn{2}{|l|}{ FEV1 } \\
\hline Median (range, $\mathrm{ml}$ ) & $1830(590-4400)$ \\
\hline FEV1/FVC & \\
\hline Median (range, \%) & $73.3(38.2-87.0)$ \\
\hline$\% \mathrm{DLCO}$ & \\
\hline Median (range, \%) & $72.2(25.4-237.0)$ \\
\hline
\end{tabular}

PS, Performance status; RBE, relative biological effectiveness; CTV, clinical target volume; VC, vital capacity; FEV1, forced expiratory volume in 1 second; FVC, forced vital capacity; \%DLCO, percent of diffusing capacity for carbon monoxide. 

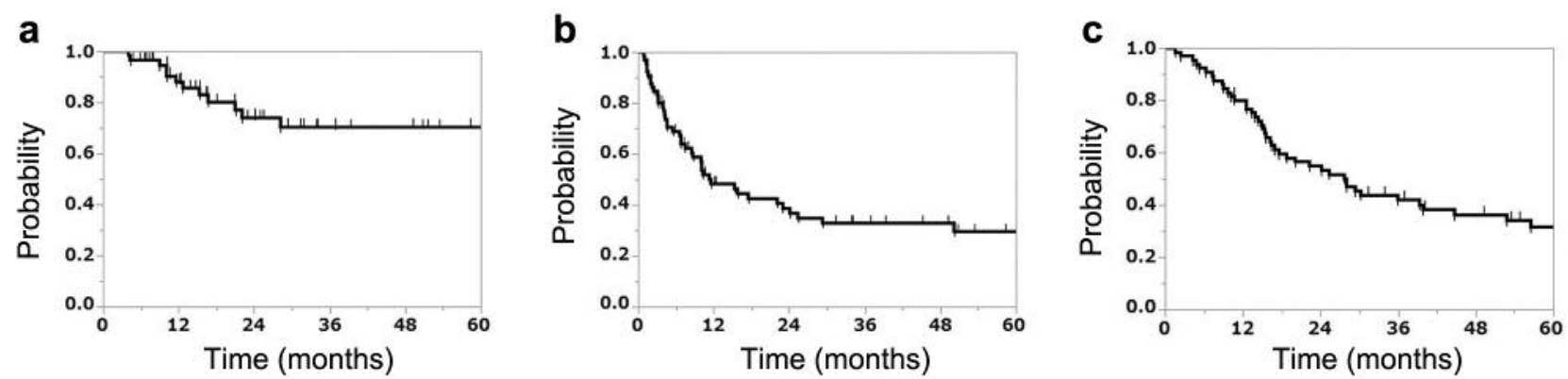

Figure 1. Local control rate (a), progression-free survival rate (b) and overall survival rate (c).

Acute and late toxicities were graded according to the National Cancer Institute's Common Terminology Criteria for Adverse Events (version 4.0).

Statistical analysis. Local control (LC), progression-free survival (PFS), and OS were calculated using the Kaplan-Meier method. All the parameters were defined as intervals starting from the date of reirradiation commencement. LC was defined till the date of local tumour regrowth in the PTV or the last follow-up. PFS was defined till the date of disease progression at any site, death from any cause, or the last follow-up. OS was defined till death or the last follow-up.

Univariate analysis was performed using the generalized Wilcoxon test to determine the prognostic factors of LC, PFS, and OS. The patients were divided into subgroups according to the median values of age, total dose, the CTV, the CIRT treatment timing (before or after January 2005), vital capacity (VC), forced expiratory volume in the first second (FEV1), the ratio of the FEV1 to the forced vital capacity (FVC), and percent predicted diffusing capacity for carbon monoxide (\%DLCO). A two-tailed $p$-value $<0.05$ was considered statistically significant. All statistical analyses were conducted using JMP statistical software (version 14.0; SAS Institute Inc., Cary, NC, USA).

\section{Results}

Patient characteristics. CIRT was discontinued in 2 patients, owing to radiation pneumonitis in 1 patient after receiving 67.5 Gy (RBE) in 15 fractions and owing to exacerbation of interstitial pneumonitis in 1 patient after receiving 71.25 Gy (RBE) in 15 fractions. Consequently, 63 patients (97\%) completed CIRT alone.

The patient and tumour characteristics are summarized in Table I. The median patient age was 73 years. Overall, 10 $(15 \%), 22(34 \%), 13(20 \%)$, and $20(31 \%)$ patients had $\mathrm{T} 1$, $\mathrm{T} 2, \mathrm{~T} 3$, and T4 disease, respectively. Moreover, 13 (20\%), 7 $(11 \%), 40(62 \%)$, and $5(8 \%)$ patients had N0, N1, N2, and N3 disease, respectively. Furthermore, $45(69 \%)$ patients had Stage IIIA NSCLC and 20 (31\%) had Stage IIIB NSCLC.

Local control and survival. The median follow-up period was 27.6 months (range=1.6-207.7 months) for all patients and 51.4 months for survivors. At the end of the follow-up,
Table II. Toxicities observed in patients with Stage III non-small cell lung cancer after carbon-ion radiotherapy.

\begin{tabular}{lcccc}
\hline Grade & $\begin{array}{c}2 \\
\mathrm{n}(\%)\end{array}$ & $\begin{array}{c}3 \\
\mathrm{n}(\%)\end{array}$ & $\begin{array}{c}4 \\
\mathrm{n}(\%)\end{array}$ & $\begin{array}{c}\text { Total } \\
\mathrm{n}(\%)\end{array}$ \\
\hline Dermatitis & $10(15)$ & 0 & 0 & $10(15)$ \\
Esophagitis & $3(5)$ & 0 & 0 & $3(5)$ \\
Pneumonitis & $7(11)$ & $4(6)$ & 0 & $11(17)$ \\
Brachial plexopathy & $2(3)$ & 0 & 0 & $2(3)$ \\
Pneumothorax & $1(2)$ & 0 & 0 & $1(2)$ \\
Chest wall pain & $1(2)$ & 0 & 0 & $1(2)$ \\
Bronchial fistula & 0 & $1(2)$ & 0 & $1(2)$ \\
Mediastinal haemorrhage & 0 & 0 & $1(2)$ & $1(2)$ \\
\hline
\end{tabular}

16 patients survived, 31 died of cancer, and 18 died of unrelated causes. At the first relapse, local recurrence was observed in 7 patients, regional recurrence in 10 (in the regional lymph nodes or/and satellite nodes in the ipsilateral lung), and distant metastases in 24.

The median PFS and OS were 10.1 and 27.6 months, respectively. The 2-year and 3-year PFS rates were $38.6 \%$ (95\% confidence interval $[\mathrm{CI}]=27.0 \%-51.7 \%$ ) and $32.8 \%$ (95\% CI $=21.9 \%-46.1 \%$ ), respectively (Figure 1b). The 2year and 3-year OS rates were 54.9\% (95\% CI=42.7\%$66.6 \%)$ and $42.0 \%(95 \% \mathrm{CI}=30.5 \%-54.4 \%)$, respectively (Figure 1c). The 2-year and 3-year LC rates were $73.9 \%$ $(95 \% \mathrm{CI}=58.2 \%-85.2 \%)$ and $70.2 \%(95 \% \mathrm{CI}=53.8 \%-82.7 \%)$, respectively (Figure 1a).

Toxicities. No patient developed Grade $\geq 3$ acute toxicity (Table II). Regarding late toxicities, 1 patient $(2 \%)$ developed Grade 4 mediastinal haemorrhage, $4(6 \%)$ developed Grade 3 radiation pneumonitis, and $1(2 \%)$ developed Grade 3 bronchial fistula. The information about the patient with Grade 4 mediastinal haemorrhage was reported previously (11). 
Table III. Univariate analysis of local control, progression-free survival, and overall survival.

\begin{tabular}{|c|c|c|c|c|}
\hline & & Local control & Progression-free survival & Overall survival \\
\hline Factors & No of patients & $p$-Value & $p$-Value & $p$-Value \\
\hline Age & & 0.620 & 0.552 & 0.421 \\
\hline$\geq 73$ years & 30 & & & \\
\hline$<73$ years & 35 & & & \\
\hline Gender & & 0.381 & 0.558 & 0.734 \\
\hline Male & 52 & & & \\
\hline Female & 13 & & & \\
\hline Smoking status & & 0.127 & 0.080 & 0.141 \\
\hline Current or previous & 51 & & & \\
\hline Never & 14 & & & \\
\hline Neoadjuvant chemotherapy & & 0.165 & 0.772 & 0.951 \\
\hline Administered & 18 & & & \\
\hline Not administered & 47 & & & \\
\hline Location of the primary tumour & & 0.818 & 0.182 & 0.205 \\
\hline Upper or Middle lobe & 55 & & & \\
\hline Lower lobe & 10 & & & \\
\hline Resection status & & 0.726 & 0.294 & 0.438 \\
\hline Resectable & 11 & & & \\
\hline Unresectable & 54 & & & \\
\hline Clinical $\mathrm{T}$ stage & & 0.248 & $<0.001$ & 0.002 \\
\hline $\mathrm{T} 1-2$ & 32 & & & \\
\hline $\mathrm{T} 3-4$ & 33 & & & \\
\hline Clinical N stage & & 0.189 & 0.017 & 0.008 \\
\hline No & 13 & & & \\
\hline $\mathrm{N} 1-3$ & 52 & & & \\
\hline Clinical stage & & 0.520 & 0.232 & 0.352 \\
\hline IIIA & 45 & & & \\
\hline IIIB & 20 & & & \\
\hline Histology of the primary lung cancer & & 0.997 & 0.098 & 0.312 \\
\hline Adenocarcinoma & 28 & & & \\
\hline Squamous cell carcinoma & 23 & & & \\
\hline Others & 14 & & & \\
\hline Total dose & & 0.687 & 0.845 & 0.941 \\
\hline$<72$ Gy RBE & 11 & & & \\
\hline$\geq 72$ Gy RBE & 54 & & & \\
\hline CTV at re-irradiation & & 0.193 & 0.057 & 0.101 \\
\hline$<423 \mathrm{ml}$ & 32 & & & \\
\hline$\geq 423 \mathrm{ml}$ & 33 & & & \\
\hline Timing of CIRT & & 0.139 & 0.050 & 0.038 \\
\hline Before January 2005 & 31 & & & \\
\hline After January 2005 & 34 & & & \\
\hline $\mathrm{VC}$ & & 0.262 & 0.367 & 0.356 \\
\hline$\geq 2840 \mathrm{~cm}^{3}$ & 33 & & & \\
\hline$<2840 \mathrm{~cm}^{3}$ & 32 & & & \\
\hline FEV1 & & 0.228 & 0.366 & 0.436 \\
\hline$\geq 1830 \mathrm{~cm}^{3}$ & 32 & & & \\
\hline$<1830 \mathrm{~cm}^{3}$ & 33 & & & \\
\hline FEV1/FVC & & 0.684 & 0.532 & 0.657 \\
\hline$\geq 73.3 \%$ & 33 & & & \\
\hline$<73.3 \%$ & 32 & & & \\
\hline$\%$ DLCO & & 0.885 & 0.628 & 0.196 \\
\hline$\geq 72.2 \%$ & 33 & & & \\
\hline$<72.2 \%$ & 32 & & & \\
\hline
\end{tabular}

RBE, Relative biological effectiveness; CTV, clinical target volume; CIRT, carbon-ion radiotherapy; VC, vital capacity; FEV1, forced expiratory volume in 1 second; FVC, forced vital capacity; \%DLCO, percent of diffusing capacity for carbon monoxide. 
a

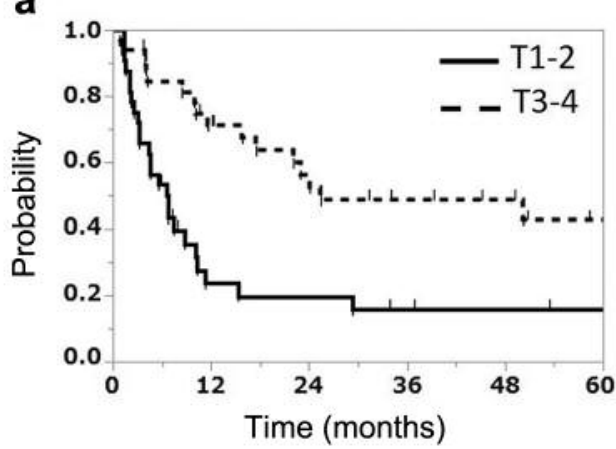

b

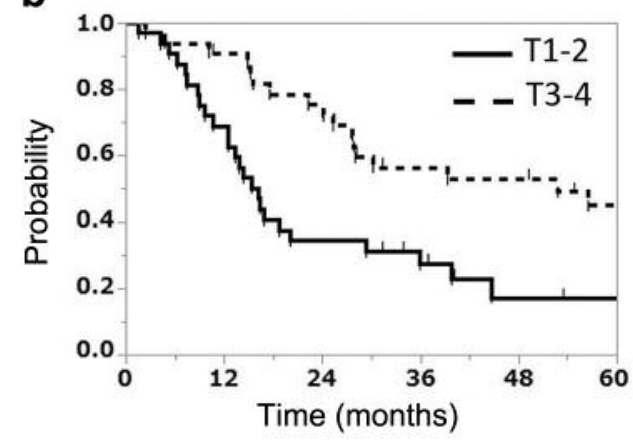

Figure 2. Progression-free survival rate (a) and overall survival rate (b) according to the T stage.

a

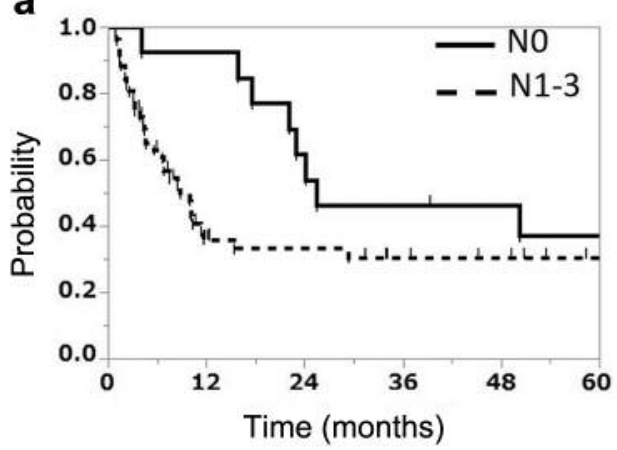

b

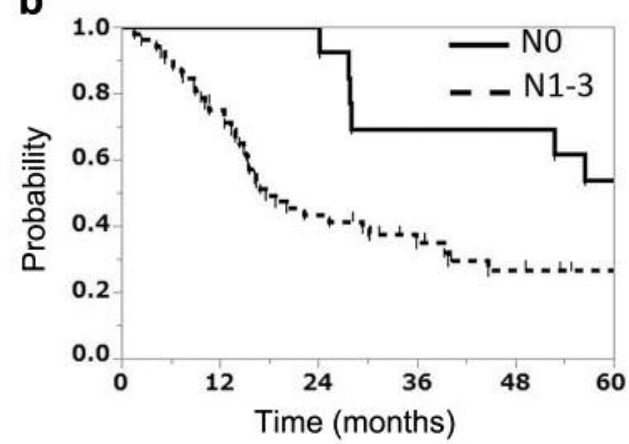

Figure 3. Progression-free survival rate (a) and overall survival rate (b) according to the $N$ stage.

Prognostic factors. The results of univariate analyses to identify potential prognostic factors are shown in Table III. On univariate analysis, the clinical $\mathrm{T}$ stage, clinical $\mathrm{N}$ stage, and the timing of CIRT (before or after January 2005) were significant predictors of PFS and OS, and CTV was a significant predictor of PFS. The 2-year PFS and OS rates of patients with T1-2 disease versus those with T3-4 disease were $19.8 \%$ versus $56.2 \%$ and $34.4 \%$ versus $75.2 \%$, respectively (Figure 2). The 2-year PFS and OS rates of patients with N0 disease versus those with N1-3 disease were $61.5 \%$ versus $33.2 \%$ and $100 \%$ versus $43.4 \%$, respectively (Figure 3). Considering the timing of CIRT, the 2-year PFS and OS rates before vs after January 2005 were $34.6 \%$ versus $41.1 \%$ and $41.9 \%$ versus $66.8 \%$, respectively (Figure 4 ). The 2-year PFS rates of patients with CTV $<423 \mathrm{ml}$ versus those with CTV $\geq 423 \mathrm{ml}$ were $41.8 \%$ versus $35.5 \%$ (Figure 5).

\section{Discussion}

To the best of our knowledge, the current study is the first to evaluate the efficacy and safety of CIRT alone only for Stage III NSCLC. Our findings demonstrated that CIRT alone resulted in high $\mathrm{LC}$ and moderate survival with acceptable toxicity, and that the $\mathrm{T}$ stage, $\mathrm{N}$ stage, and the timing of CIRT were significant predictors of PFS and OS. In studies that evaluated the efficacy and safety of platinumbased concurrent chemoradiotherapy for patients with Stage III NSCLC, the median PFS and OS were 9.5-13.3 months and 22.0-28.7 months, respectively (1-3). In addition, another phase III trial compared the anti-programmed death ligand 1 antibody durvalumab as consolidation therapy after concurrent chemoradiotherapy for Stage III NSCLC with a placebo (4). In that study, PFS was significantly longer after durvalumab treatment (median $\mathrm{PFS}=16.8$ months) than after placebo treatment (median $\mathrm{PFS}=5.6$ months), although analysis of the OS was not planned at the time of the interim analysis. In another study, proton beam radiotherapy and concurrent chemotherapy were administered for Stage III NSCLC; the median PFS and OS were 12.9 months and 26.5 months, respectively (12). The present study revealed that the median PFS and OS for Stage III NSCLC were 10.1 months and 27.6 months, respectively. Our findings indicate that CIRT alone is as efficacious as photon or proton concurrent chemoradiotherapy when we consider the fact 

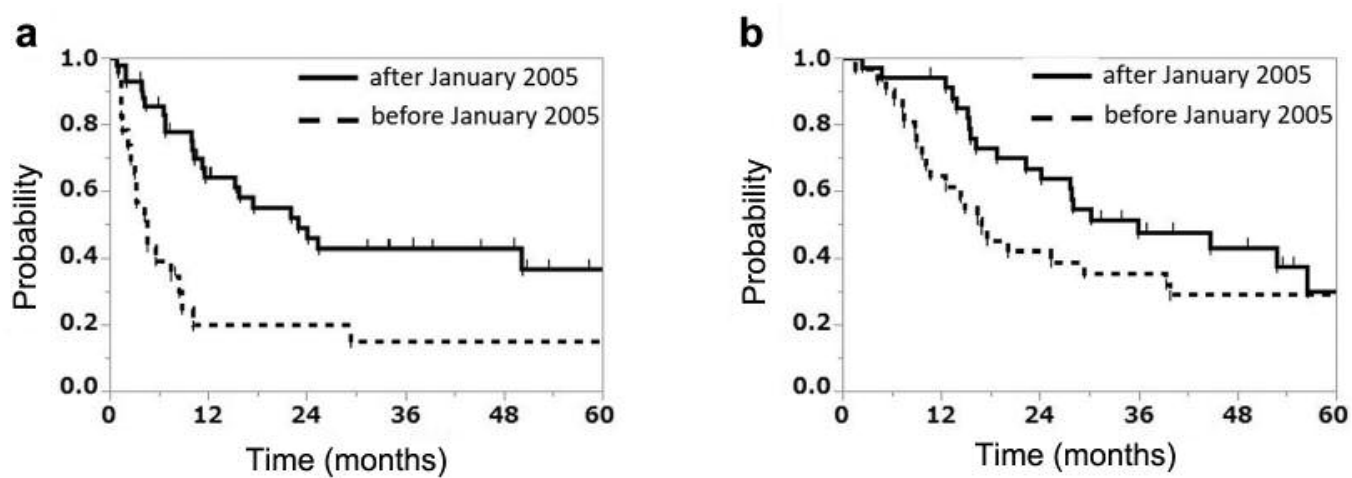

Figure 4. Progression-free survival rate (a) and overall survival rate (b) according to the timing of CIRT. CIRT, Carbon-ion radiotherapy.

that the median age of the patients in the present study (73 years) was higher than the median age of the patients in the above-mentioned chemoradiotherapy studies (63-64 years), durvalumab study (64 years), or proton study (70 years).

Regarding Grade $\geq 3$ toxicity, hematological toxicity is the most frequent complication after concurrent chemoradiotherapy and consolidation therapy for Stage III NSCLC. In fact, $>50 \%$ of patients treated with concurrent chemoradiotherapy developed Grade $\geq 3$ leukopenia, anaemia, and/or thrombocytopenia (1-3). In contrast, in the current study, none of the patients treated with CIRT experienced any hematological toxicity, because CIRT results in minimal irradiation to the bone marrow. Among nonhematological toxicities, radiation pneumonitis and esophagitis are major complications (1-3). After photon chemoradiotherapy, the incidence of Grade $\geq 3$ pneumonitis and esophagitis was $4.1 \%-10 \%$ and $7 \%-14 \%$, respectively (1-3). Moreover, Grade 3 or 4 adverse events occurred in $29.9 \%$ of the patients who received durvalumab; the most common adverse event was pneumonia (4.4\%). Furthermore, after proton beam concurrent chemotherapy for Stage II or III NSCLC, the incidence of Grade $\geq 3$ pneumonitis and esophagitis was $10.5 \%-12 \%$ and $6 \%$ $12 \%$, respectively (12-14). In contrast, in the current study using CIRT alone, Grade 3 radiation pneumonitis occurred in only $6 \%$ of all patients and none of the patients developed Grade $\geq 4$ radiation pneumonitis and Grade $\geq 3$ esophagitis. Thus, our findings indicate that, considering Grade $\geq 3$ toxicity, CIRT alone may be safer than photon chemoradiotherapy and consolidation therapy or proton chemoradiotherapy.

On univariate analysis, we found that the T1-2 classification, N1-3 classification, and the former part about the timing of CIRT were significant poor prognostic factors of PFS and OS, and that CTV $\geq 423 \mathrm{ml}$ was a significant poor prognostics factor of PFS. Similar to the findings of previous studies $(8,10)$, the $\mathrm{N}$ stage and timing of CIRT were identified as poor prognostic factors. The result that the prognosis of patients with T1-2 disease is poorer than that of patients with T3-4 disease may have arisen from the

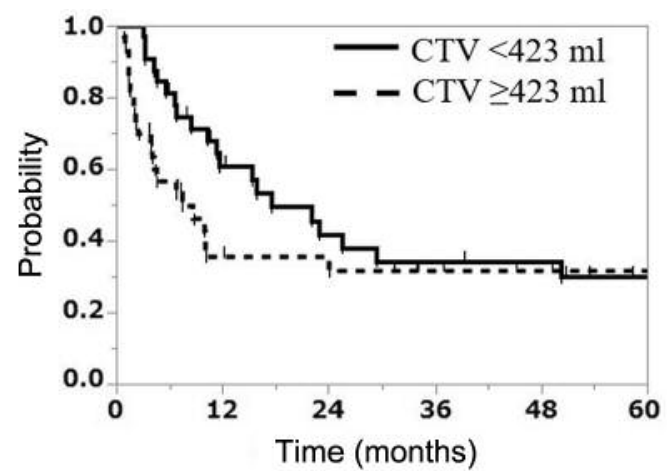

Figure 5. Progression-free survival rate according to the CTV. CTV, Clinical target volume.

difference of the metastatic potential between T1-2 and T34 disease. According to the TNM classification, Stage III includes T3N1-3 and T4N0-3 but only T1-2N2-3. In other words, the T1-2 tumours in our study were more progressive lung cancers than the T3-4 tumours considering the presence of metastatic lymph nodes. Moreover, patients with T1-2 disease in our study seemed to have more indolent distant metastasis than the patients with T3-4 disease did, especially before January 2005 considering the timing of CIRT. In fact, stage migration was noted because minimal metastasis was partially detected owing to the improvement in the imaging diagnostic technology such as PET and CT $(15,16)$. Before January 2005, considering the timing of CIRT, PFS and OS of patients with T1-2 disease were significantly poorer than those of patients with T3-4 disease, but after January 2005, there was no significant difference in PFS and OS between patients with T1-2 disease and patients with T3-4 disease (Figure 6). This is probably because recent imaging techniques have excluded patients who have minimal distant metastases, especially many patients with T1-2N2-3 disease. 

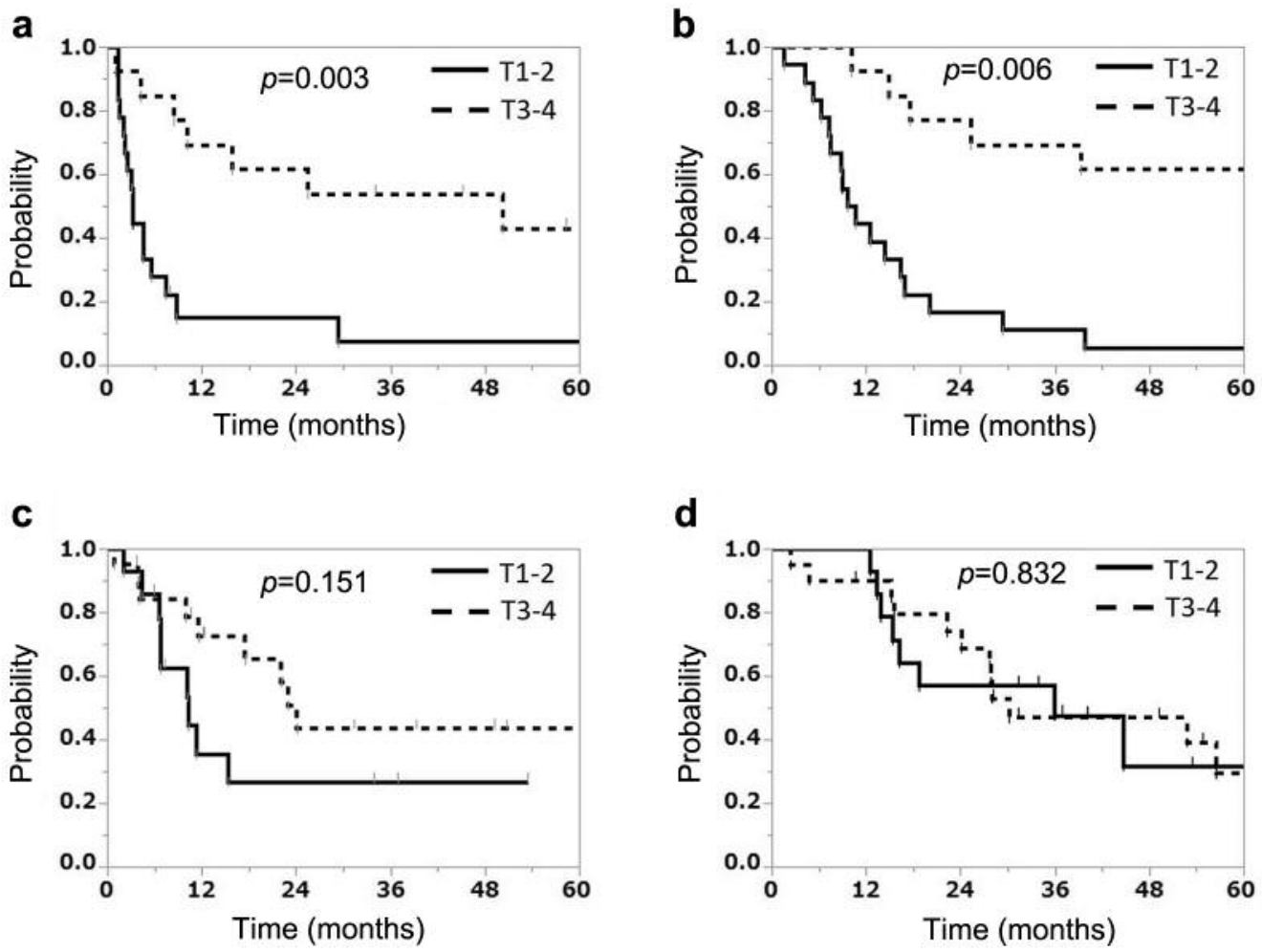

Figure 6. Progression-free survival rate (a) and overall survival rate (b) according to the T stage of patients with Stage III non-small-cell lung cancer who underwent CIRT before January 2005; progression-free survival rate (c) and overall survival rate (d) according to the $T$ stage of patients with Stage III non-small-cell lung cancer who received CIRT after January 2005 CIRT, carbon-ion radiotherapy.

The current study had several limitations. First, the study was a single-centre retrospective analysis with a small sample size $(\mathrm{N}=65)$. Therefore, selection bias may exist. Second, the late toxicity might be underestimated, because the median follow-up duration (27.6 months) was not sufficient. Finally, the total doses varied [64-76 Gy (RBE) in 16 fractions]. Therefore, further large-scale multicentre prospective trials are needed.

In conclusion, CIRT alone is an effective treatment with acceptable toxicity for Stage III NSCLC and is a reasonable treatment option, especially for patients with Stage III lung cancer with N0 classification or T3-4 classification.

\section{Conflicts of Interest}

The Authors have no conflicts of interest.

\section{Authors' Contributions}

AM designed the study with support from YN and HK, and wrote the initial draft of the manuscript. YN and HK contributed to analysis and interpretation of data, and assisted in the preparation of the manuscript. All other Authors have contributed to data collection and interpretation, and critically reviewed the manuscript.
All Authors approved the final version of the manuscript, and agree to be accountable for all aspects of the work in ensuring that questions related to the accuracy or integrity of any part of the work are appropriately investigated and resolved.

\section{Acknowledgements}

The Authors would like to thank the members of the NIRS Working Group for Lung Cancer. We also wish to thank Editage (www.editage.jp) for English language editing. This research did not receive any specific grant from funding agencies in the public, commercial, or not-for-profit sectors.

\section{References}

1 Segawa Y, Kiura K, Takigawa N, Kamei H, Harita S, Hiraki S, Watanabe Y, Sugimoto K, Shibayama T, Yonei T, Ueoka H, Takemoto M, Kanazawa S, Takata I, Nogami N, Hotta K, Hiraki A, Tabata M, Matsuo $\mathrm{K}$ and Tanimoto $\mathrm{M}$ : Phase III trial comparing docetaxel and cisplatin combination chemotherapy with mitomycin, vindesine, and cisplatin combination chemotherapy with concurrent thoracic radiotherapy in locally advanced non-small-cell lung cancer: OLCSG 0007. J Clin Oncol 28(20): 3299-3306, 2010. PMID: 20530281. DOI: 10.1200/JCO.2009.24.7577 
2 Bradley JD, Paulus R, Komaki R, Masters G, Blumenschein G, Schild S, Bogart J, Hu C, Forster K, Magliocco A, Kavadi V, Garces YI, Narayan S, Iyengar P, Robinson C, Wynn RB, Koprowski C, Meng J, Beitler J, Gaur R, Curran W and Choy $\mathrm{H}$ : Standard-dose versus high-dose conformal radiotherapy with concurrent and consolidation carboplatin plus paclitaxel with or without cetuximab for patients with stage IIIA or IIIB non-smallcell lung cancer (RTOG 0617): a randomised, two-by-two factorial p. Lancet Oncol 16(2): 187-99, 2015. PMID: 25601342. DOI: $10.1016 / \mathrm{S} 1470-2045(14) 71207-0$

3 Yamamoto N, Nakagawa K, Nishimura Y, Tsujino K, Satouchi M, Kudo S, Hida T, Kawahara M, Takeda K, Katakami N, Sawa T, Yokota S, Seto T, Imamura F, Saka H, Iwamoto Y, Semba H, Chiba Y, Uejima H and Fukuoka M: Phase III study comparing second- and third-generation regimens with concurrent thoracic radiotherapy in patients with unresectable stage III non-smallcell lung cancer: West Japan Thoracic Oncology Group WJTOG0105. J Clin Oncol 28(23): 3739-3745, 2010. PMID: 20625120. DOI: 10.1200/JCO.2009.24.5050

4 Antonia SJ, Villegas A, Daniel D, Vicente D, Murakami S, Hui R, Yokoi T, Chiappori A, Lee KH, de Wit M, Cho BC, Bourhaba M, Quantin X, Tokito T, Mekhail T, Planchard D, Kim Y-C, Karapetis CS, Hiret S, Ostoros G, Kubota K, Gray JE, Paz-Ares L, de Castro Carpeño J, Wadsworth C, Melillo G, Jiang H, Huang Y, Dennis PA, Özgüroğlu M and PACIFIC Investigators: Durvalumab after chemoradiotherapy in stage III non-small-cell lung cancer. N Engl J Med 377(20): 1919-1929, 2017. PMID: 28885881. DOI: 10.1056/NEJMoa1709937

5 Gajra A and Jatoi A: Non-small-cell lung cancer in elderly patients: a discussion of treatment options. J Clin Oncol 32(24): 2562-2569, 2014. PMID: 25071101. DOI: 10.1200/JCO.2014.55.3099

6 Atagi S, Kawahara M, Yokoyama A, Okamoto H, Yamamoto N, Ohe Y, Sawa T, Ishikura S, Shibata T, Fukuda H, Saijo N, Tamura $\mathrm{T}$ and Japan Clinical Oncology Group Lung Cancer Study Group: Thoracic radiotherapy with or without daily low-dose carboplatin in elderly patients with non-small-cell lung cancer: a randomised, controlled, phase 3 trial by the Japan Clinical Oncology Group (JCOG0301). Lancet Oncol 13(7): 671-678, 2012. PMID: 22622008. DOI: 10.1016/S1470-2045(12)70139-0

7 Kanai T, Endo M, Minohara S, Miyahara N, Koyama-ito H, Tomura H, Matsufuji N, Futami Y, Fukumura A, Hiraoka T, Furusawa Y, Ando K, Suzuki M, Soga F and Kawachi K: Biophysical characteristics of HIMAC clinical irradiation system for heavy-ion radiation therapy. Int J Radiat Oncol Biol Phys 44(1): 201-210, 1999. PMID: 10219815. DOI: 10.1016/s03603016(98)00544-6

8 Takahashi W, Nakajima M, Yamamoto N, Yamashita H, Nakagawa K, Miyamoto T, Tsuji H, Kamada T and Fujisawa T: A prospective nonrandomized phase I/II study of carbon ion radiotherapy in a favorable subset of locally advanced non-small cell lung cancer (NSCLC). Cancer 121(8): 1321-1327, 2015. PMID: 25641119. DOI: $10.1002 /$ cncr.29195
9 Karube M, Yamamoto N, Shioyama Y, Saito J, Matsunobu A, Okimoto T, Ohno T, Tsuji H, Nakano T and Kamada T: Carbonion radiotherapy for patients with advanced stage non-small-cell lung cancer at multicenters. J Radiat Res 58(5): 761-764, 2017. PMID: 28992088. DOI: 10.1093/jrr/rrx037

10 Hayashi K, Yamamoto N, Nakajima M, Nomoto A, Tsuji H, Ogawa $\mathrm{K}$ and Kamada T: Clinical outcomes of carbon-ion radiotherapy for locally advanced non-small-cell lung cancer. Cancer Sci 110(2): 734-741, 2019. PMID: 30467928. DOI: $10.1111 /$ cas. 13890

11 Hayashi K, Yamamoto N, Karube M, Nakajima M, Matsufuji N, Tsuji H, Ogawa K and Kamada T: Prognostic analysis of radiation pneumonitis: carbon-ion radiotherapy in patients with locally advanced lung cancer. Radiat Oncol 12(9): 91, 2017. PMID: 28558766. DOI: 10.1186/s13014-017-0830-z

12 Chang JY, Verma V, Li M, Zhang W, Komaki R, Lu C, Allen PK, Liao Z, Welsh J, Lin SH, Gomez D, Jeter M, O'Reilly M, Zhu RX, Zhang X, Li H, Mohan R, Heymach JV, Vaporciyan AA, Hahn S and Cox JD: Proton beam radiotherapy and concurrent chemotherapy for unresectable stage III non-small cell lung cancer. JAMA Oncol 3(8): e172032, 2017. PMID: 28727865. DOI: $10.1001 /$ jamaoncol.2017.2032

13 Elhammali A, Blanchard P, Yoder A, Liao Z, Zhang X, Ronald Zhu X, Allen PK, Jeter M, Welsh J and Nguyen QN: Clinical outcomes after intensity-modulated proton therapy with concurrent chemotherapy for inoperable non-small cell lung cancer. Radiother Oncol 136: 136-142, 2019. PMID: 31015115. DOI: $10.1016 /$ j.radonc.2019.03.029

14 Liao Z, Lee JJ, Komaki R, Gomez DR, O’Reilly MS, Fossella F V, Blumenschein GR, Heymach J V, Vaporciyan AA, Swisher SG, Allen PK, Choi NC, DeLaney TF, Hahn SM, Cox JD, Lu $\mathrm{CS}$ and Mohan R: Bayesian adaptive randomization trial of passive scattering proton therapy and intensity-modulated photon radiotherapy for locally advanced non-small-cell lung cancer. J Clin Oncol 36(18): 1813-1822, 2018. PMID: 29293386. DOI: 10.1200/JCO.2017.74.0720

15 Morgensztern D, Goodgame B, Baggstrom MQ, Gao F and Govindan R: The effect of FDG-PET on the stage distribution of non-small cell lung cancer. J Thorac Oncol 3(2): 135-139, 2008. PMID: 18303433. DOI: 10.1097/JTO.0b013e3181622c2c

16 Chee KG, Nguyen DV, Brown M, Gandara DR, Wun T and Lara PN Jr.: Positron emission tomography and improved survival in patients with lung cancer: the Will Rogers phenomenon revisited. Arch Intern Med 168(14): 1541, 2008. PMID: 18663166. DOI: 10.1001/archinte.168.14.1541

Received November 7, 2019

Revised November 26, 2019 Accepted November 29, 2019 